JOSING: Journal of Nursing and Health

Volume 1, Nomor 1, Desember 2020

e-ISSN: $2745-7877$

p-ISSN: 2746-0851

DOI: https://doi.org/10.31539/josing.v1i1.1244

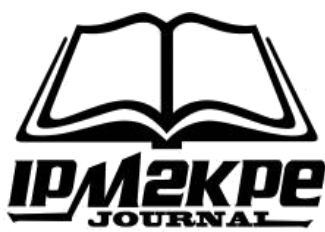

\title{
TREATMENT UNDER THE SPOTLIGHT AND KANGURU MOTHER CARE FOR BODY TEMPERATURE AMONG PREMATURE NEWBORN
}

\author{
Jasper Suinite Pole \\ Port Moresby General Hospital, Papua New Guinea \\ jasper2020@gmail.com
}

\begin{abstract}
The purpose of this study was to find out how the comparison between kangaroo cares methods and treatments under the spotlight to control the body temperature of premature infants in the perinatology room port moresby general hospital, papua new guinea. This type of research is an experiment with a posttest only control design. The results obtained Mann-Whitney value of 0.589, which means the value of p-value> rather than $\alpha$ (0.05). Conclusion, there was no significant difference between the control group (under the spotlight treatment) and the intervention group (kangaroo maintenance method).
\end{abstract}

Keywords: Kangaroo Mother Care, Premature newborn, Spotlights

\section{INTRODUCTION}

According to data from UNICEF (2013), under-five mortality has been relatively high in Africa and the South Asia region. In South East Asia, infant mortality in 2013 are generally less than 20 deaths per 1,000 live births in the countries that have shown better economic performance (Febriyuna, 2015) . On the other hand, Infant Mortality Rate (IMR) has decreased by $60.48 \%$ from 62 per 1,000 live births in 1990 to become 24.5 per 1,000 live births in 2013. The reduction of children who died in the first month of their lives has declined by 54.48\%; from 31 per 1,000 live births in 1990 to become 14 per 1,000 live births in 2013. The regression results form a previous study shows that bio-demographic factors which include child and maternal traits are key predictors of infant mortality in Indonesia. Male sex, birth multiplicity, higher birth rank, shorter birth interval, mother age above 35 years, and complication during pregnancy are positively related to infant mortality (Situmorang, 2019).

Low weight babies (LBW) and premature is the highest contributor to infant mortality in Indonesia. Considering the severity of the problems that may occur in LBW and premature babies, various efforts must be made by caring for the baby specifically and even intensively. Understanding various factors related to infant problems can be the basis in preventing or solving problems (Bergh et al., 2012; Berkat, Sutan, 2014).

Low birth weight babies (LBW) are babies whose weight is less than 2500 grams without regard to gestational age, while premature babies are babies born before 37 weeks' gestation regardless of body weight (Bergh et al., 2012). Others describes LBW babies may be premature (less months), maybe also quite months. Low birth weight babies (LBW) and premature have special needs in maintaining and improving their health. Meeting these basic needs is very dependent on the care provider (Cutland et al., 2017). Premature low weight babies (LBW) are very vulnerable to illness and death due to the characteristics of immature organs. Premature birth infection and hypothermia, 
respiratory disorder are the highest causes of death in Indonesia (Adisasmita, Izati, 2017). Infants are prone to hypothermia because the ability to retain heat and ability to increase heat production is very limited due to inadequate muscle growth, little subcutaneous fat and immature nervous system temperature regulation. Body surface area is relatively larger compared to body weight so it is easy to lose heat (Fitriani, 2018).

Nowadays, premature babies usually treated in incubators or under radiant heaters (Okken, Koch, 2012). According to Fitriani (2018) three primary methods to maintain a thermal temperature environment are the use of incubators, radiant heating panels and an open basinet with a cotton blanket. The use of mechanical equipment is faced with problems of lack of skilled labor, equipment maintenance costs, and logistics. In addition, the use of incubators is considered to inhibit the mother-baby early contact and breastfeeding, as well as result in mothers lacking confidence and unskilled care for their children. To overcome this need an alternative method that is cheap and effective, one of which is through Kangaroo Mother care (KMC) or skin contact between baby and mother or father (Silva et al., 2016; Lee et al., 2014).

Port Moresby General Hospital, Papua New Guinea is a central referral hospital so that the number of LBW infants is quite high in January-June 2017 were 1572 babies with 460 LBW infants $(29.26 \%)$ both cesarean section delivery, vacuum extraction, forcef extraction or spontaneous. There are 6 units of incubators available in the Perinatology Room which are not only used by LBW and premature babies but also by sepsis babies. Thus many LBW and premature babies who should be treated in an incubator do not get proper care. LBW infants and premature babies are treated under the spotlight and are not allowed to be admitted together.

Nurses provide counseling about FMD to mothers or parents who have premature babies by providing an explanation of the benefits of the kangaroo method and if interested mothers are advised to come to the Perinatology room for demonstrations. With this method the results achieved from January-June 2011 there were 32 (6.96\%) premature babies who did the kangaroo method while 428 babies did not use the kangaroo method. From interviews conducted on nurses who served in the Perinatology room, amounting to 12 people found that 8 nurses $(75 \%)$ believe that the kangaroo method is safe for premature babies in the implementation of partial rooming in, while 3 nurses $(25 \%)$ are still hesitant to carry out partial rooming in for premature babies with the kangaroo method for reasons of fear of the baby being cold. By looking at this phenomenon, the author would like to examine the effect of kangaroo method treatments on controlling the body temperature of premature babies in the Perinatology Room of Port Moresby General Hospital, Papua New Guinea.

\section{RESEARCH METHODS}

This research is an experimental study in which the research subjects are COPD patients in Buleleng District Hospital, because in the study it provides treatment or intervention on the object to be studied. The design used in this study is one group pretest and post-test. Conduct a pre-test to determine the oxygen saturation value in COPD patients before breathing relaxation techniques are used with ballon blowing techniques. After that provide breathing relaxation techniques with ballon blowing techniques in COPD patients for 5-10 minutes for 4 weeks. 
A post test was conducted to see changes in oxygen saturation. The sampling technique used was non-probability sampling (total sampling) with a sample size of 30 respondents. The ethical review in this study was conducted by the Health Research Ethics Committee (KEPK) of Buleleng College of Health Sciences.

\section{RESULT}

Table. 1

Data on Research Results in the Control Group

(Treatment Under the Spotlight)

\begin{tabular}{ccccccc}
\hline No. & $\begin{array}{c}\text { Gestational } \\
\text { Age } \\
\text { (weeks) }\end{array}$ & $\begin{array}{c}\text { Weight } \\
\text { (gram) }\end{array}$ & $\begin{array}{c}\text { Temperature } \\
\text { to-0 } \\
\left({ }^{\circ} \mathrm{C}\right)\end{array}$ & $\begin{array}{c}\text { Temperature } \\
\text { to- } 1 \\
\left({ }^{\circ} \mathrm{C}\right)\end{array}$ & $\begin{array}{c}\text { Temperature } \\
\text { to-2 } \\
\left({ }^{\circ} \mathrm{C}\right)\end{array}$ & $\begin{array}{c}\text { Average } \\
\left({ }^{\circ} \mathrm{C}\right)\end{array}$ \\
\hline 1. & 36 & 1700 & 37,2 & 37,4 & 37,5 & 37,45 \\
2. & 36 & 1800 & 37,2 & 36,9 & 36,9 & 36,90 \\
3 & 36 & 1600 & 36,7 & 36,5 & 37,0 & 36,75 \\
4 & 36 & 1900 & 37,0 & 37,3 & 38,0 & 37,65 \\
5 & 34 & 2050 & 37.0 & 36,7 & 37,0 & 36,85 \\
6 & 36 & 2200 & 36.7 & 37,0 & 37,2 & 37,00 \\
7 & 36 & 2350 & 36,7 & 37,0 & 37,4 & 37,20 \\
8 & 35 & 2300 & 37,0 & 37,8 & 38,3 & 38,05 \\
9 & 35 & 2200 & 37,2 & 38,9 & 39,3 & 39,10 \\
10 & 34 & 1900 & 36,9 & 38,1 & 37,9 & 38,00 \\
11 & 35 & 2200 & 36,6 & 37,0 & 37,9 & 37,45 \\
12 & 33 & 2100 & 37,1 & 36,9 & 37,3 & 37,10 \\
13 & 36 & 2300 & 36,8 & 37,0 & 37,3 & 37,15 \\
14 & 34 & 1900 & 36,9 & 37,2 & 37,1 & 37,15 \\
15 & 34 & 1750 & 36,9 & 37,5 & 38,1 & 37,80 \\
\hline
\end{tabular}

From the above data the mean temperature of the first is $37.28 \mathrm{oC}$, the temperature $\geq 37.5$ there are 3 respondents $(20 \%)$ with temperatures between $37.5-38.9^{\circ} \mathrm{C}$. the second mean temperature is $37.6^{\circ} \mathrm{C}$, the temperature $\geq 37.5$ there are 7 respondents (46.67\%) with temperatures between 37.5-39.3oC.

Table. 2

Data on Research Results in the Intervention Group

(Kangaroo Maintenance Method)

\begin{tabular}{ccccccc}
\hline No. & $\begin{array}{c}\text { Gestational } \\
\text { Age } \\
\text { (weeks) }\end{array}$ & $\begin{array}{c}\text { Weight } \\
\text { (gram) }\end{array}$ & $\begin{array}{c}\text { Temperature } \\
\text { to-0 } \\
\left({ }^{\circ} \mathrm{C}\right)\end{array}$ & $\begin{array}{c}\text { Temperature } \\
\text { to }-1 \\
\left({ }^{\circ} \mathrm{C}\right)\end{array}$ & $\begin{array}{c}\text { Temperature } \\
\text { to }-2 \\
\left({ }^{\circ} \mathrm{C}\right)\end{array}$ & $\begin{array}{c}\text { Average } \\
\left({ }^{\circ} \mathrm{C}\right)\end{array}$ \\
\hline 1 & 35 & 2100 & 36,7 & 37,3 & 37,5 & 37,40 \\
2 & 36 & 2000 & 36,5 & 37,0 & 37,3 & 37,15 \\
3 & 36 & 2350 & 37,4 & 37,3 & 37,7 & 37,50 \\
4 & 36 & 2300 & 36,5 & 37,1 & 37,4 & 37,25 \\
5 & 35 & 2100 & 37,0 & 37,7 & 37,9 & 37,80 \\
6 & 36 & 2000 & 36,8 & 37,5 & 38,5 & 38,00 \\
7 & 36 & 2300 & 36,8 & 37,2 & 37,3 & 37,25 \\
8 & 36 & 2250 & 36,8 & 37,1 & 36,9 & 37,00 \\
9 & 34 & 1850 & 36,8 & 37,0 & 37,0 & 37,00 \\
10 & 34 & 1800 & 37,0 & 37,2 & 37,0 & 37,10 \\
11 & 35 & 1900 & 37,2 & 37,6 & 37,9 & 37,75 \\
12 & 34 & 1750 & 37,0 & 37,4 & 37,5 & 37,45 \\
\hline
\end{tabular}




\begin{tabular}{rrrrrrr}
\hline 13 & 33 & 1750 & 37,0 & 36,9 & 37,2 & 37,05 \\
14 & 34 & 1700 & 36,5 & 36,8 & 36,6 & 36,70 \\
15 & 34 & 1600 & 36,6 & 36,7 & 36,7 & 36,70 \\
\hline
\end{tabular}

From the above data the mean temperature of the first is $37.19^{\circ} \mathrm{C}$, the temperature $\geq 37.5$ there are 3 respondents $(20 \%)$ with temperatures between $37.5-37.7^{\circ} \mathrm{C}$. the second mean temperature is $37.36^{\circ} \mathrm{C}$, the temperature $\geq 37.5$ there are 6 respondents (40\%) with temperatures between 37.5-38.5oC.

\section{Univariate Analysis}

Table. 3

Distribution of Gestational Age in the Control and Intervention Groups in the Perinatology Room of port Moresby General Hospital,

Papua New Guinea $(\mathrm{n}=15)$

\begin{tabular}{lcccc}
\hline \multicolumn{1}{c}{ Variable } & Mean & SD & Min - Mak & Value p \\
\hline $\begin{array}{l}\text { Age of gestation } \\
\text { (Control group) }\end{array}$ & 35,0 & 1,03280 & $33-36$ & 0,610 \\
\hline $\begin{array}{l}\text { Age of gestation } \\
\text { (Intervention group) }\end{array}$ & 34,9333 & 1,03280 & $33-36$ & 0,610 \\
\hline
\end{tabular}

The results obtained in the control group were mean gestational age of 35 weeks, with a standard deviation of 1.03280. Whereas in the intervention group, mean gestational age was 34.9333 weeks. Statistical test results obtained p value $=0.610$ which means that at $\alpha=5 \%$ it appears that there is no significant difference in gestational age in the control group and the intervention group.

Table. 4

Weight Distribution in the Control Group and the Intervention Group in the Perinatology Room of Port Moresby General Hospital, Papua New Guinea $(\mathrm{n}=15)$

\begin{tabular}{ccccc}
\hline Variable & Mean & SD & Min - Mak & Nilai p \\
\hline $\begin{array}{c}\text { Weight } \\
\text { (Control group) }\end{array}$ & 2017 & 241,0295 & $1600-2350$ & 0,687 \\
\hline $\begin{array}{c}\text { Weight } \\
\text { (intervention group) }\end{array}$ & 1980 & 239,6426 & $1600-2350$ & 0.687 \\
\hline
\end{tabular}

The results were obtained in the control group which is the mean body weight of 2017 grams, with a standard deviation of 241.0295. Whereas in the intervention group the mean body weight was 1980 grams, with a standard deviation of 239,6426. From the results of statistical tests the results of statistical tests obtained $p$ value $=0.687$ which means that at $\alpha=5 \%$ it appears that there is no significant difference in body weight in the control group and the intervention group. 
Table. 5

Results of Mann-Whitney Test Analysis of Average Temperatures in the Control Group and the Intervention Group in the Perinatology Room of Port Moresby General Hospital,

Papua New Guinea

\begin{tabular}{cccc}
\hline Variabel & Mean Rank & Sum of Rank & P \\
\hline $\begin{array}{c}\text { Average temperature } \\
\text { (control group) }\end{array}$ & 16,37 & 245,50 & 0,589 \\
\hline $\begin{array}{c}\text { Average temperature } \\
\text { (intervention group) }\end{array}$ & 14,63 & 219,50 & \\
\hline
\end{tabular}

Based on table 5 the analysis results obtained Mann-Whitney value of 0.589 which means the value of $p>$ rather than $\alpha(0.05)$. The conclusion drawn is, Ho is accepted which means there is no significant difference between the control group (treatment under the spotlight) with the intervention group (kangaroo method treatment).

\section{DISCUSSION}

\section{Characteristics of Respondents}

Based on the research objective is to find out how the effect of kangaroo method treatment on the control of the body temperature of premature infants, the results obtained that the control of body temperature in preterm infants in the group treated under the spotlight and the kangaroo method treatment group there was no significant difference. This is evidenced by the results of the average temperature in preterm infants treated under the floodlight that is $37.44^{\circ} \mathrm{C}$ while the average temperature in premature babies with kangaroo care methods is $37.27^{\circ} \mathrm{C}$. The results obtained provide information that the treatment of kangaroo methods and baby care under the spotlight can control body temperature in premature babies, in addition to other factors that can affect body temperature. In the control group (treatment under the spotlight) results obtained in the second body temperature measurements, respondents who temperature $\geq 37.5$ were 3 respondents $(20 \%)$ and in the body temperature measurements were 3 respondents respondents whose body temperature $\geq 37,5$ as many as 7 respondents $(46.67 \%)$, this is due to the influence of the hot spotlights which can lead to an increase in environmental temperature which has an effect on temperature regulation (Lee et al., 2014; et al, 2017),

Also supported that premature infants whose central body temperature regulation has not perfectly developed so that it can cause an increase in body temperature. In the intervention group the results obtained in the measurement of the body temperature of the 2 respondents whose temperature $\geq 37.5^{\circ} \mathrm{C}$ as many as 3 respondents $(20 \%)$ and on the measurement of body temperature the 3 respondents whose temperature $\geq 37.5^{\circ} \mathrm{C}$ as many as 6 respondents (40\%), this is due to some mothers using cessaria section labor, mothers are still in the inflammatory phase in this phase the mother occurs the body's defense mechanism, tissue damaged by the incision release a small molecular protein (pyrogen) into a blood vessel, which is then phagocyted by microfags, which will release Interleukin-1 which then stimulates the hypothalamus which will be stimulated to synthesize prostaglandin E2 and neorostransmitters which cause the temperature at the set point to increase, through increased metabolism, decreased sweat production, and vasoconstriction of blood vessels on the surface of the body, resulting in an increase in body temperature (Okken, Koch, 2012). 
In this phase the mother also experiences pain in her abdominal area. When being treated kangaroo method can cause anxiety for the mother for fear of the baby pressing the abdomen. Anxiety is a symptom of stress, both physical stress and emotional stress. The stress causes stimulation of epineprin and nonepinephrin, so that the speed of metabolism will increase resulting in an increase in body temperature (Rao et al., 2019; Salarmanesh et al., 2018). Kangaroo care methods and treatments under the floodlights result in body temperature in controlled preterm infants. With the treatment of the kangaroo method can prevent heat loss by conduction and evaporation. While in care under the floodlight the baby receives heat by radiation from the spotlight so as to prevent the process of heat loss in the baby. Others study shows skin to skin contact can provide comfort to the baby and can cause peripheral blood vessels to prevent blood from reaching the surface of the body. This mechanism is stimulated in the sympathetic nervous system, and then the peripheral nervous system will trigger the muscles around the skin arterioles to contract so that vasoconstriction occurs. This situation is effective in reducing blood flow to the skin tissue and preventing excessive heat loss (Kostandy, Ludington-Hoe, 2019).

By positioning the baby between the breast and upright position, the baby's chest attaches to the mother's chest. The baby's head is turned to the right or left side, and with the position slightly raised (extension). The baby's groin should be in the flexed and wide position as in the "frog" position; the hand must be in a flexed position. When the baby is cold, the baby cannot shiver so the baby increases the level of activity by crying and positioning the hands and feet in a flexed position to produce heat (Grayson, 2018).

Rao et al., (2019) also confirmed that by doing kangoroo model, stabilizing the body temperature $\left(36.5-37.5^{\circ} \mathrm{C}\right)$, the baby's heart rate is relatively stable around $140-160$ $\mathrm{x} /$ minute, and oxygen saturation around 90-100\%. Warms the baby, increases sleep duration, reduces baby's crying and calorie requirements, accelerates weight gain and brain development, enhances emotional connection between mother and baby, increases success and prolongs breastfeeding duration. The benefits of kangoroo care for mothers, facilitate breastfeeding, mothers are more confident in caring for the baby, close relationships between mothers and mothers longer, dear mothers to their babies, the psychological influence of calmness for mothers and babies (mothers are more satisfied less stressed). The benefits of kangoroo method for fathers, fathers play a greater role in caring for their babies, increasing the relationship between fathers and babies, especially playing an important role in countries with high levels of child abuse. It will be possible to reflect upon his attitudes as caregiver and get him closer to the newborn child. Therefore, it is possible to strengthen the behaviors between father and son with the purpose of creating an emotional bond, thus allowing the inherent care regarding prematurity. Understanding the paternal behavior in the care of the premature child in the kangaroo method and their perceptions about care neonatal, can benefit nursing praxis from the perspective of promoting neonatal health, as well as in the prevention of diseases in relation to morbidity and infant mortality. (Lopes et al., 2019; Srinath et al., 2016).

On the 4 other hand, the advantage arising from the use of spotlights in incubator is easy to access for observation and procedures and can increase body temperature quickly. While the disadvantages are high transepidermal water loss which causes problems with fluid balance, difficulty giving extra moisture, high heat loss by convection (Padila, Agustien, 2019; Yeler, Koseoglu, 2020). 
Benefits of kangaroo care is the length of stay of the baby in the hospital is shorter so that it can prevent the occurrence of infection in the baby and the efficiency of nurses because the mother is more caring for her own baby and the workload of officers will be reduced (Albishry et al., 2018). Reducing the use of facilities (electricity, incubators, and other sophisticated tools) so that they can help with budget efficiency. With the increase in turn over and budget efficiency it is expected that there will be an increase in income. In order for the implementation of kangaroo care methods to be carried out, it is necessary to have a policy that is continuous training, motivation of nurses in implementing KMC and evaluation and supervision.

There are no losses incurred from the kangaroo method, but the difficulty that can be obtained during the treatment room is that the mother is still afraid and hesitant to take care of the kangaroo method because she sees the condition of her baby being small and looking weak.Seeing the many benefits of kangaroo method treatment, it would be better if premature babies who had met the requirements for kangaroo method treatment, could carry out kangaroo method treatment continuously or intermittently.

\section{CONCLUSION}

Based on the results of the study it was found that the average temperature of premature infants using spotlight treatments was $37.44^{\circ} \mathrm{C}$, and those using kangaroo treatments were $37.27 \mathrm{oC}$, with a $\mathrm{p}$ value $=0.589$ concluded that there was no significant difference between treatments under the lamp highlight with the kangaroo care method.

Care of the kangaroo method and care under the spotlight results in body temperature in controlled premature babies. With the treatment of the kangaroo method can prevent heat loss by conduction and evaporation. While in care under the floodlight the baby receives heat by radiation from the spotlight so as to prevent the process of heat loss in the baby.

The advantage arising from the use of spotlights is that it is easy to access for observation and procedures and can increase body temperature quickly. While the disadvantages are high transepidermal water loss which causes problems with fluid balance, difficulty giving extra moisture, high heat loss by convection.

Advantages of treatment Kangaroo method is the length of stay of the baby in the hospital becomes shorter so that it can prevent infection in infants and can stabilize the body temperature of premature babies $\left(36.5-37.5^{\circ} \mathrm{C}\right)$.

The average change in temperature of the kangaroo method is smaller compared to the treatment under a spotlight, which means there is a tendency for hyperthermia to occur in premature infants treated under the spotlight, due to the process of heat transfer by radiation from the spotlight to baby's body.

\section{SUGGESTION \\ For Institutions}

The results of this study can be used to determine later methods for the care of premature babies. As well as to make or develop SOPs on discharge planning for kangaroo care, the need for socialization of nursing SOPs, especially kangaroo care SOPs and the evaluation of kangaroo care SOP activities in the room. 


\section{Nursing Profession}

The role of the nurse as an educator for the patient and the patient's family, in this case the nurse can provide education to parents who have premature babies about the care of the kangaroo method. Routinely evaluating and monitoring the implementation of kangaroo care methods so that nursing care can be better and more effective.

\section{Educational Institution}

This research can be used as input for educational institutions, kangaroo method care material can be included in one of the teaching materials, especially about premature baby care.

\section{For Further Research}

The results of this study are used as basic data in subsequent studies. This study has limitations, especially from the condition of the mother, therefore it is necessary to do further research using the same characteristics of the mother, especially from the type of delivery and by using more samples.

\section{REFERENCES}

Adisasmita, A., \& Izati, Y. (2017). Characteristics of Asphyxiated Newborn Babies in Referral Hospitals of Banten Province, Indonesia. II Proceeding Book, 54

Albishry, S. N., Shouk, M. E., Alkhaldi, S., Almowlad, N., \& Omer, T. (2018). The Effectiveness of Kangaroo Mother Care (KMC) on Premature Infant Health Progression in a Neonatal Care Unit in Maternity and Children's Hospital, Jeddah. Int J Nurs Didact, 8(09), 27-33. DOI: 10.15520/ijnd.v8i09.2307

Bergh, A.-M., Charpak, N., Ezeonodo, A., Udani, R. H., \& Van Rooyen, E. (2012). Education and Training in the Implementation of Kangaroo Mother Care. South African Journal of Child Health, 6(2), 38-45

Berkat, S., \& Sutan, R. (2014). The Effect of Early Initiation of Breastfeeding on Neonatal Mortality among Low Birth Weight in Aceh Province, Indonesia: an unmatched case control study. Advances in Epidemiology

Cutland, C. L., Lackritz, E. M., Mallett. M. T., Bardají, A., Chandrasekaran, R., Lahariya, C., \& Kochhar, S. (2017). Low Birth Weight: Case Definition \& Guidelines for Data Collection, Analysis, and Presentation of Maternal Immunization Safety Data. Vaccine, 35(48Part A), 6492

Febriyuna, N. (2015). Determinants of Infant Mortality in Indonesia. The Hague, The Netherlands

Fitriani, M. U. (2018). Effectiveness of Early Initiation of Nursing Hypothermia Prevention in Newborn. Journal of Ultimate Public Health, 2(2), 119-123

Grayson, C. E. (2018). Kangaroo Care Is Effective in Diminishing Pain Response in Preterm Neonates(2003), by Celeste Johnston, Bonnie Stevens, Janet Pinelli, Sharyn Gibbins, Francoise Filion, Anne Jack, Susan Steele, Kristina Boyer, and Annie Veilleux. Embryo Project Encyclopedia

Kostandy, R. R., \& Ludington-Hoe, S. M. (2019). The Evolution of the Science of Kangaroo (Mother) Care (Skin-to-Skin Contact). Birth defects research, 111(15), 1032-1043

Lee, E. J., Kim, E. S., Lee, Y. N., Park, S. H., Lee, G. M., \& Yi, Y. H. (2014). Development of the Kangaroo Care Protocol and its Effect on Premature Infants. Journal of Korean Clinical Nursing Research, 20(3), 313-325 
Lopes, T. R. G., Santos, V. E. P., \& Carvalho, J. B. L. d. (2019). The Presence of the Father in the Kangaroo Method. Escola Anna Nery, 23(3)

Okken, A., \& Koch, J. (2012). Thermoregulation of Sick and Low Birth Weight Neonates: Temperature Control. Temperature Monitoring. Thermal Environment: Springer Science \& Business Media

Padila, P., \& Agustien, I. (2019). Suhu Tubuh Bayi Prematur di Inkubator Dinding Tunggal dengan Inkubator Dinding Tunggal Disertai Sungkup. Jurnal Keperawatan Silampari, 2(2), 113-122

Rao, P., Raajashri, R., Bethou, A., Bhat, V., \& Palanivel, C. (2019). Does Kangaroo Mother Care Reduce Anxiety in Postnatal Mothers of Preterm Babies?-A Descriptive Study from a Tertiary Care Centre in South India. Journal of Nepal Health Research Council, 17(1), 42-45

Salarmanesh, A., Khafri, S., Mouodi, S., \& Arzani, A. (2018). The Effect of Kangaroo Mother Care on Mental Health of Mothers with Premature Infants. Journal of Babol University of Medical Sciences, 20(6), 7-13

Silva, M. G., Barros, M. C., Pessoa, Ú. M. L., \& Guinsburg, R. (2016). KangarooMother Care Method and Neurobehavior of Preterm Infants. Early Human Development, 95, 55-59

Situmorang, H. E. (2019). Health Worker Perceptions about Factors that Contribute to Infant Mortality in Indonesia. Flinders University: College of Nursing and Health Sciences

Srinath, B., Shah, J., Kumar, P., \& Shah, P. (2016). Kangaroo Care by Fathers and Mothers: Comparison of Physiological and Stress Responses in Preterm Infants. Journal of Perinatology, 36(5), 401-404

Vahdati, M., Mohammadizadeh, M., \& Talakoub, S. (2017). Effect of Kangaroo Care Combined with Music on the Mother-Premature Neonate Attachment: A Randomized Controlled Trial. Iranian Journal of Nursing and Midwifery Research, 22(5), 403

Yeler, O., \& Koseoglu, M. F. (2020). Optimization and Experimental Validation of a Modular Thermoelectric Heat Pump System for a Premature Baby Incubator. Journal of Electronic Materials, 1-14 